\title{
Novel method for holocellulose analysis of non-woody biomass wastes
}

\author{
Ana Álvarez ${ }^{a}$, Sofía Cachero ${ }^{a}$, Carlos González-Sánchez ${ }^{\mathrm{a}}$, Jose Montejo-Bernardo ${ }^{\mathrm{b}}$, Consuelo Pizarro $^{\mathrm{a}, \text { *, }}$ \\ Julio L. Bueno ${ }^{a}$ \\ a Department of Chemical and Environmental Engineering, Faculty of Chemistry, University of Oviedo, Ave. Julián Clavería, 33006, Oviedo, Spain \\ b Department of Physical-Analytical Chemistry, University of Oviedo, Ave. Julián Clavería, 33006, Oviedo, Spain
}

\section{A R T I C L E I N F O}

\section{Keywords:}

Non-woody biomass

Compositional analysis

Biomass ternary diagram

Holocellulose

Crystallinity index

\begin{abstract}
A B S T R A C T
Compositional analysis of non-woody biomass is quite important to determine its possible applications. However, current standard methods developed for woody biomass compositional analysis have been revealed to be unsuitable when applied to non-woody biomass. Therefore, a novel and less-time consuming modified method which enables for a proper isolation of holocellulose in non-woody biomass samples while increasing lignin degradation has been developed. The novel method mainly consists in a treatment with sodium chlorite and glacial acetic acid at boiling point, which precludes changes in the holocellulose crystallinity degree or losses of carbohydrates, as shown by DSC, XRPD, and HPLC analysis. It was successfully applied to the determination of the structural components of 10 different non-woody biomass samples. Also, its use revealed that non-woody biomass belongs to LHC and LCH groups in the biomass structural composition ternary diagram, which are completely different than the ones the woody biomass belongs to.
\end{abstract}

\begin{tabular}{|c|c|}
\hline \multicolumn{2}{|c|}{ List of Acronyms } \\
\hline Cel70 & Cellulose obtained from hollocellulose 70 (Holo70) \\
\hline Cel96 & Cellulose obtained from hollocellulose 70 (Holo96) \\
\hline CHL & $\begin{array}{l}\text { Biomass group whose cellulose content }>\text { hemicellulose } \\
\text { content }>\text { lignin content }\end{array}$ \\
\hline CLH & $\begin{array}{l}\text { Biomass group whose cellulose content }>\text { lignin con- } \\
\text { tent }>\text { hemicellulose content }\end{array}$ \\
\hline DSC & Differential scanning calorimetry \\
\hline HCL & $\begin{array}{l}\text { Biomass group whose hemicellulose content }>\text { cellulose } \\
\text { content }>\text { lignin content }\end{array}$ \\
\hline HLC & $\begin{array}{l}\text { Biomass group whose hemicellulose content }>\text { lignin } \\
\text { content }>\text { cellulose content }\end{array}$ \\
\hline Holo70 & Holocellulose obtained by following the ASTM standard \\
\hline Holo96 & $\begin{array}{l}\text { Holocellulose obtained by following the novel method } \\
\text { proposed }\end{array}$ \\
\hline HPLC & High-performance liquid chromatography \\
\hline IC & Crystallinity index \\
\hline
\end{tabular}

LCH Biomass group whose lignin content $>$ cellulose content $>$ hemicellulose content

LHC Biomass group whose lignin content $>$ hemicellulose content $>$ cellulose content

MCC Commercial microcrystaline cellulose

SEM Scanning electron microscopy

XRPD X-ray powder diffraction

\section{Introduction}

Olive oil extraction, as well as table olive and fruits production, represent highly relevant economic activities in wide areas of Europe -such as the Mediterranean countries- and in the rest of the world, as well (Rodríguez et al., 2008). Taking into account the input and output mass balance of the olive oil industry, the crops' yield and the cultivated area, only the amounts of olive stone and olive pomace in Europe are estimated to be of 2,012,211 t/year and 4,724,322 t/year, respectively (Agencia Andaluza de la Energía, 2016; elEconomista.es, 2017; Eurostat, 2015; Rosúa \& Pasadas, 2012; Secretaría General Técnica and Subdirección General de Estadística, 2016).

\footnotetext{
* Corresponding author.

Email address: pizarroconsuelo@uniovi.es (C. Pizarro)
} 
Olive non-woody wastes like those aforementioned, as well as non-woody grapevine and fruit production wastes, could find several applications, such as eco-friendly adsorbents (Vecino, Devesa-Rey, Cruz, \& Moldes, 2015), cosmetic and therapeutic products (Moudache, Colon, Nerín, \& Zaidi, 2016), and energy production. Also, their upgrading would enable the increase of the profitability of olive and fruit producers as well as wineries; the reduction of fossil fuels dependence for different agricultural and industrial activities, as well as the reduction of carbon footprint.

In spite of the aforementioned potential applications and advantages, non-woody wastes remain underused. This is due to the lack of knowledge about the composition of the different non-woody wastes of several species, which is, for instance, quite important for the evaluation of conversion yields in biofuels production industry (Sluiter, Ruiz, Scarlata, Sluiter, \& Templeton, 2010). Also, in order to determine the possible uses of a specific type of biomass is important to classify it in the ternary diagram. The ternary diagram divides biomass into six different organic structural types: CHL, CLH, HCL, LCH, HLC, and LHC. The classification of a biomass in the ternary diagram requires an accurate determination of its composition (Vassilev, Vassileva, \& Vassilev, 2015) and is a key step for establishing a normalized biomass classification and to determining the possible use of biomass wastes, too.

Previous compositional analysis results for woody biomass have shown that this kind of biomass belongs to the groups which have higher quantities of cellulose such as CLH and CHL (Álvarez et al., 2015). The main compositional analysis method to determine the content of the structural components in a biomass sample is the summative mass closure, which consists in the determination of lignin and holocellulose by means of an acid hydrolysis with sulphuric acid according to NREL TP-510-42618 method (Sluiter et al., 2008). The solid residue is the acid-insoluble lignin and ashes, while the hydrolysates are the monomers and dimers of holocellulose and a minor part of the lignin called acid soluble lignin. Thus, this method gives information about the amount of holocellulose in the sample through the hydrolysates. However, if it is needed to isolate holocellulose as a solid fraction, the method proposed in this paper enables an appropriate one-step quantification and isolation of the holocellulose fraction. This is really important in order to study the properties of this fraction in some applications such as the holocellulose use as filler in composite materials, whose mechanical properties may be affected by the lignin presence in holocellulose (Angelini, Cerruti, Immirzi, Scarinzi, \& Malinconico, 2016; Šimkovic et al., 2017). In addition, holocellulose is the starting-point of most work in carbohydrates study of biomass (Rabemanolontsoa \& Saka, 2012). The most common methods used to isolate holocellulose are the Wise method (Wise, 1946) and the ASTM D1104 standard method based on the Wise's one (ASTM International, 1978). These methods consist in subjecting biomass samples to a specific number of acid chlorination stages in order to remove the lignin using a sodium chlorite and glacial acetic acid mixture.

Previous research works on non-woody biomass give an extremely high total summative or data of the structural composition normalised to $100 \%$, because of the inability of the standard methods to achieve a proper separation of the lignin and holocellulose fractions of non-woody biomass samples (Álvarez et al., 2015; Demirbaş, 2001; Müller-Hagedorn, Bockhorn, Krebs, \& Müller, 2002; Rabemanolontsoa, Ayada, \& Saka, 2011). Although lignin and ash corrections could be done, in some cases there is a need for holocellulose isolation as mentioned above. To this end, a work of Rabemanolontsoa modified the Wise method for holocellulose determination in bamboo and sargasso. To prevent carbohydrate loss from the samples, they reduced the number of chlorination stages and made lignin, ash and protein corrections on crude holocellulose (Rabemanolontsoa \& Saka, 2012). Other authors (Yeh, Chang, \& Kadla, 2004) modified the reaction temperature and time as well as the amounts of reactants in order to isolate the holocellulose fraction of loblolly pine.

Also, current standard procedures (ASTM International, 1978; Sluiter et al., 2008; Wise, 1946) have been developed for woody and herbaceous biomass; however these procedures could be unsuitable for other lignocellulosic non-woody biomass, such as stones, shells or kernels, if it is necessary to isolate holocellulose as a solid fraction. A paper of Sluiter et al. highlighted the need for improved methods to characterize the components of biomass as well as the validation of the existing methods on a wider variety of biomass types (Sluiter et al., 2010). In this paper, it is shown that the standard method is unsuitable for the extraction of holocellulose from stones or shells, as the holocellulose fractions obtained following this method were brownish instead of whitish, due to the poor delignification of the samples. Therefore, this paper is devoted to a novel method for holocellulose determination for non-woody biomass. The novel method developed in this paper is based on the ASTM's one (ASTM International, 1978, but it is less time consuming and has the advantage of enhancing the degradation of lignin without any additional carbohydrate loss. That is, the novel method proposed in this paper enables a better delignification of non-woody biomass samples without changing the crystallinity nor the amount of monomers present in the isolated holocellulose.

\section{Materials and methods \\ 2.1. Samples}

Structural components of 10 non-woody biomass samples (almond shell, dry olive oil mill stone - olive stone obtained after drying process of the raw olive oil mill stone -, extracted olive pomace, extracted olive pomace pellets, hazelnut shell, nut shell, raw olive oil mill stone, olive pomace oil-extractor, raw olive stone and pine nut shell), belonging to industrial wastes, were determined following the novel method of holocellulose determination proposed in this paper.

Commercial Microcrystalline Cellulose (MCC) from Western Redcedar (Thuja plicata) was supplied by Acros Organic (Belgium) and used as a reference in DSC and XRPD analysis. It has an average particle diameter of $50 \mu \mathrm{m}$.

Commercial kraft lignin from Sigma-Aldrich (USA) was also used as a reference. It is a polymeric lignin material isolated from a commercial pulp mill using Norway Spruce as raw material. Its number and weight average molecular weights were 1750 and $14200 \mathrm{~g} / \mathrm{mol}$ respectively.

\subsection{Compositional analysis procedure}

All studied samples were ground and sieved until particle size was in the range $250-500 \mu \mathrm{m}$ (TAPPI, 2007), as a pre-treatment to sort and isolate the analyzed fractions.

To determine the structural composition of biomass waste samples, the chemical extraction sequence shown in Fig. 1 was followed. Different fractions data are expressed in dry, ash and extractives free basis. Every experimental run, except singular extractive determinations and four times holocellulose determination, was performed thrice to ensure a suitable reproducibility of experiments.

\subsubsection{Extractives fraction determination}

As shown in Fig. 1, samples were subjected to a two-stage extraction (TAPPI, 2007) in order to remove a group of substances known as "extractives" that might interfere with a rigorous characterization. The first of these stages consists in an acetone treatment of biomass samples in a Soxhlet extractor during 7-8h to get rid of resins, waxes, sterols, fats and fatty acids. The second extraction stage is carried out 


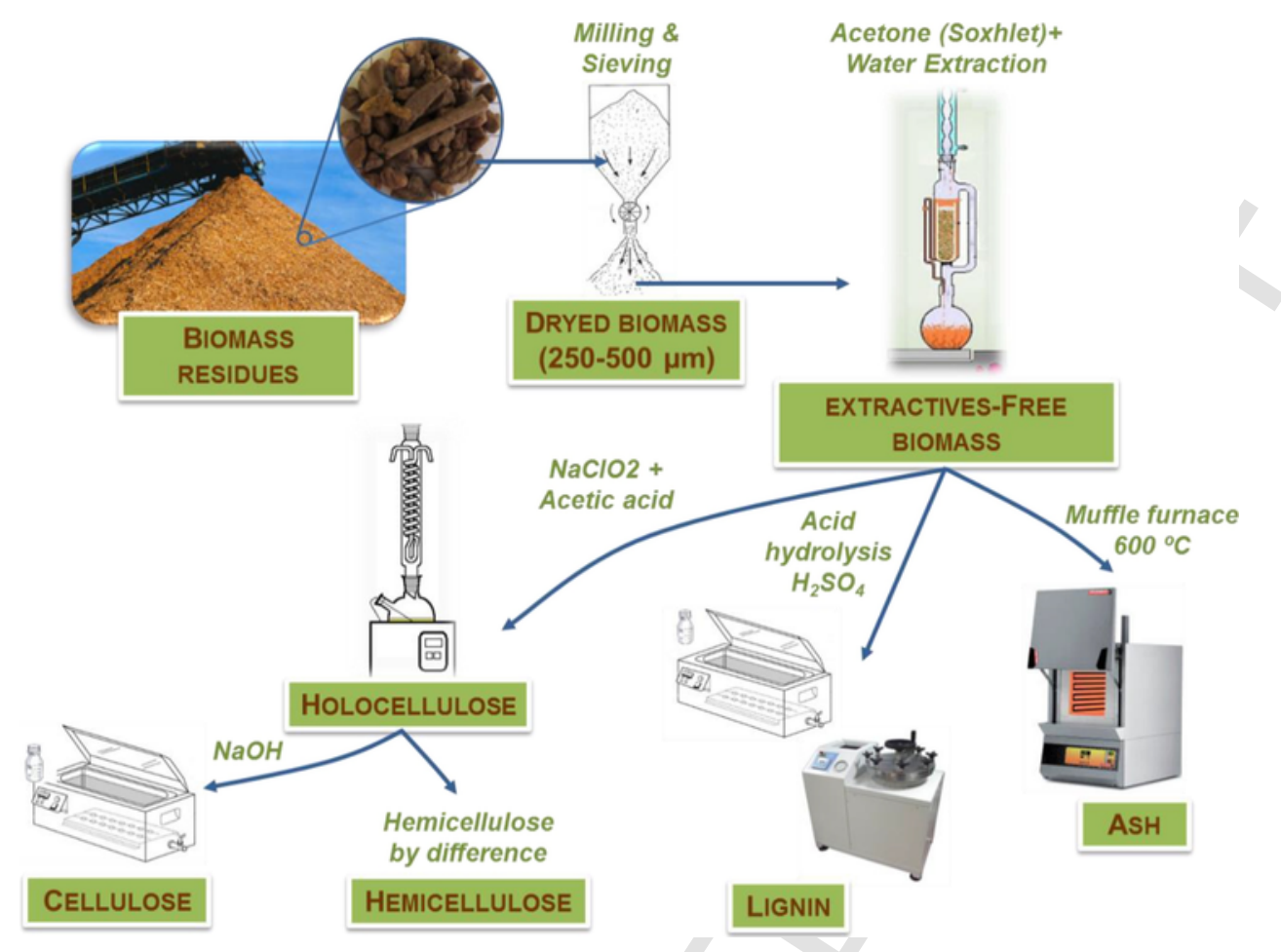

Fig. 1. Chemical extraction procedure to determine the structural composition of biomass.

with boiling water during $1 \mathrm{~h}$ in order to remove tannins, gums, sugars and colored matter. Once both stages were completed, extractives-free biomass was air-dried to reduce its moisture content below $15 \%$.

\subsubsection{Holocellulose fraction determination}

As shown in Fig. 1, this fraction was obtained from extractive-free biomass by means of a sodium chlorite and glacial acetic acid treatment at $70-80^{\circ} \mathrm{C}$. ASTM D-1104 standard (ASTM International, 1978) and the novel method were used for this purpose.

\subsubsection{Cellulose and hemicellulose fraction determination}

According to TAPPI T 212 standard, previously obtained holocellulose fractions were treated with sodium hydroxide to determine the sample cellulose content (TAPPI, 2002). Sample hemicellulose content was calculated by the difference between holocellulose and cellulose quantities.

$\%$ Hemicellulose $=\%$ Holocellulose $-\%$ Cellulose

\subsubsection{Lignin fraction determination}

Extractives-free biomass was subjected to a two-step acid hydrolysis for lignin quantification according to NREL/TP-510-42618 method (Sluiter et al., 2008). Concentrated sulphuric acid and then diluted sulphuric acid at high pressure were used. The same standard method was also used to determine the lignin content of holocellulose and cellulose fractions.

\subsubsection{Ash fraction determination}

Ash quantification was carried out according to NREL/ TP-510-42622 method (Sluiter et al., 2005). This procedure consists in a thermal treatment at $600^{\circ} \mathrm{C}$ using a muffle furnace (see Fig. 1).

\subsection{Differential scanning calorimeter}

Thermograms of cellulose and holocellulose samples were registered using a Differential Scanning Calorimeter, mod. DSC 822e (Mettler-Toledo, Switzerland), under a nitrogen atmosphere. Among other factors, DSC peak position may substantially be affected by sample mass. In addition, the heating rate may also affect peak position. For these reasons, peaks position in DSC thermograms was determined for sample masses of 5, 10, 15 and $20 \mathrm{mg}$ and heating rates of 5, 10, 15 and $20 \mathrm{~K} / \mathrm{min}$. Since the volume occupied by the different cellulosic samples in the DSC pan may vary, to keep samples weight exactly the same is quite difficult, and some peak position variations were found to be inherent to the thermal analysis of this kind of samples. However, low peak position differences were found when working with sample masses ranging between 15 and $20 \mathrm{mg}$ at a heating rate of $20 \mathrm{~K} / \mathrm{min}$. The use of the faster heating rate $(20 \mathrm{~K} / \mathrm{min})$ also avoids any possibility of sample recrystallization during the DSC experiments.

\subsection{X-ray diffraction (crystallinity index)}

Three different samples were analyzed: holocellulose obtained following the standard (Holo70) and novel (Holo96) methods and commercial microcrystalline cellulose (MCC). The crystallinity index of the raw material was determined from X-ray powder diffraction data. The X-ray diffraction was performed on an XPERT-PRO Panalytical diffractometer using side-loaded samples and CuK $\alpha$ radiation $(\lambda=1.5418 \AA)$ at $25^{\circ} \mathrm{C}$ in a range of $5^{\circ}-40^{\circ}$ with a step of $0.02^{\circ}$. Crystallinity index values were calculated by the peak subtraction method (Segal, Creely, Martin, \& Conrad, 1959; Vieira \& Pasquini, 2014) following the Eq. (1): 


$$
\mathrm{IC}=\frac{\mathrm{I}_{002}-\mathrm{I}_{\mathrm{am}}}{\mathrm{I}_{002}} \times 100
$$

where $\mathrm{I}_{002}$ is the height of the (002) peak (at $2 \theta \approx 22.5^{\circ}$ ) assumed as the crystalline signal, and $\mathrm{I}_{\mathrm{am}}$ is the height of the minimum intensity (at $2 \theta \approx 18.0^{\circ}$ ) assumed as the amorphous band.

\subsection{Determination of structural carbohydrates}

The monomers of structural carbohydrates arising from the hydrolysates of lignin determination were measured by HPLC using an Agilent 1100 system with a BioRad Aminex HPX-87C column at $80^{\circ} \mathrm{C}$ and a flow rate of milliQ water of $0.6 \mathrm{ml} / \mathrm{min}$.

\section{Results and discussion}

\subsection{Summative mass and SEM images}

The standard methods for determining holocellulose (ASTM International, 1978) and lignin (Sluiter et al., 2008) were applied to samples of non-woody biomass. Surprisingly, the sum of holocellulose and lignin was higher than $100 \%$ in most cases, as can be seen in Table 1.

Also, the holocellulose fraction obtained showed a brownish color instead of a whitish one as usual after the holocellulose determination procedure (Fig. 2). In order to ascertain the reason for this experimental result, SEM images were taken for different samples.The holocellulose fraction obtained at $70-80^{\circ} \mathrm{C}$ according to the standard procedure (Fig. 2b) showed some irregularities and a poor fibrous-like morphology due to the lignin content in this holocellulose fraction. Lignin particles, like that pointed out with a red circle in Fig. $2 \mathrm{~b}$ could also be observed. This result indicated that the standard holocellulose determination procedure could be unsuitable for non-woody biomass samples. After several unsuccessful optimizations of the standard method, the aforementioned novel method was developed. The raw olive stone sample was selected for the development of the novel method due to its high production in Spain and Europe.

Table 2 shows a comparison between the standard and the novel method proposed in this paper. Among the differences between both methods, the addition of all the reactants at the beginning of the procedure, the higher temperature used $\left(96^{\circ} \mathrm{C}\right)$ and the much lower time ( $90 \mathrm{~min}$ ) that feature the novel method can be mentioned.

As can be seen in Table 3, the results were much better when the novel method for holocellulose determination was used. To ascertain the reasons for this fact, samples of raw olive stone and its holocellulose, obtained from the standard and the novel methods, were examined by SEM. The SEM images of these samples were compared to SEM images of cherry tree holocellulose isolated according to the standard procedure (Fig. 2d). As mentioned above, the holocellulose fraction from the standard method (Fig. 2b) showed lignin particles, while no lignin particles were found to be present in the holocellulose isolated by following the novel method (Fig. 2c).

Table 1

Compositional analysis data when applying standard methods (Álvarez et al., 2015).

\begin{tabular}{|c|c|c|c|c|c|}
\hline Biomass & Extractives (\%) & Moisture (\%) & Holocellulose (\%) & Lignin (\%) & Total* $(\%)$ \\
\hline Almond shell & 8.02 & $10.2 \pm 0.2$ & $81 \pm 3$ & $33 \pm 3$ & $114 \pm 3$ \\
\hline Dry olive oil mill stone & 2.30 & $10.0 \pm 0.2$ & $88 \pm 1$ & $33.2 \pm 0.9$ & $121 \pm 1$ \\
\hline Extracted olive pomace & 67.79 & $10.6 \pm 0.1$ & $53 \pm 10$ & $40 \pm 1$ & $93 \pm 10$ \\
\hline Extracted olive pomace pellets & 55.96 & $7.0 \pm 0.2$ & $63 \pm 4$ & $38.1 \pm 0.6$ & $101 \pm 4$ \\
\hline Olive pomace oil-extractor & 36.84 & $10.5 \pm 0.3$ & $73.4 \pm 0.4$ & $34 \pm 3$ & $107 \pm 3$ \\
\hline Raw olive oil mill stone & 7.99 & $10.1 \pm 0.3$ & $89 \pm 1$ & $34.7 \pm 0.6$ & $123 \pm 1$ \\
\hline Raw olive stone & 2.29 & $9.29 \pm 0.04$ & $95 \pm 2$ & $36.8 \pm 0.3$ & $132 \pm 2$ \\
\hline Total $=$ Holocellulose + Lignin & & & & & \\
\hline
\end{tabular}

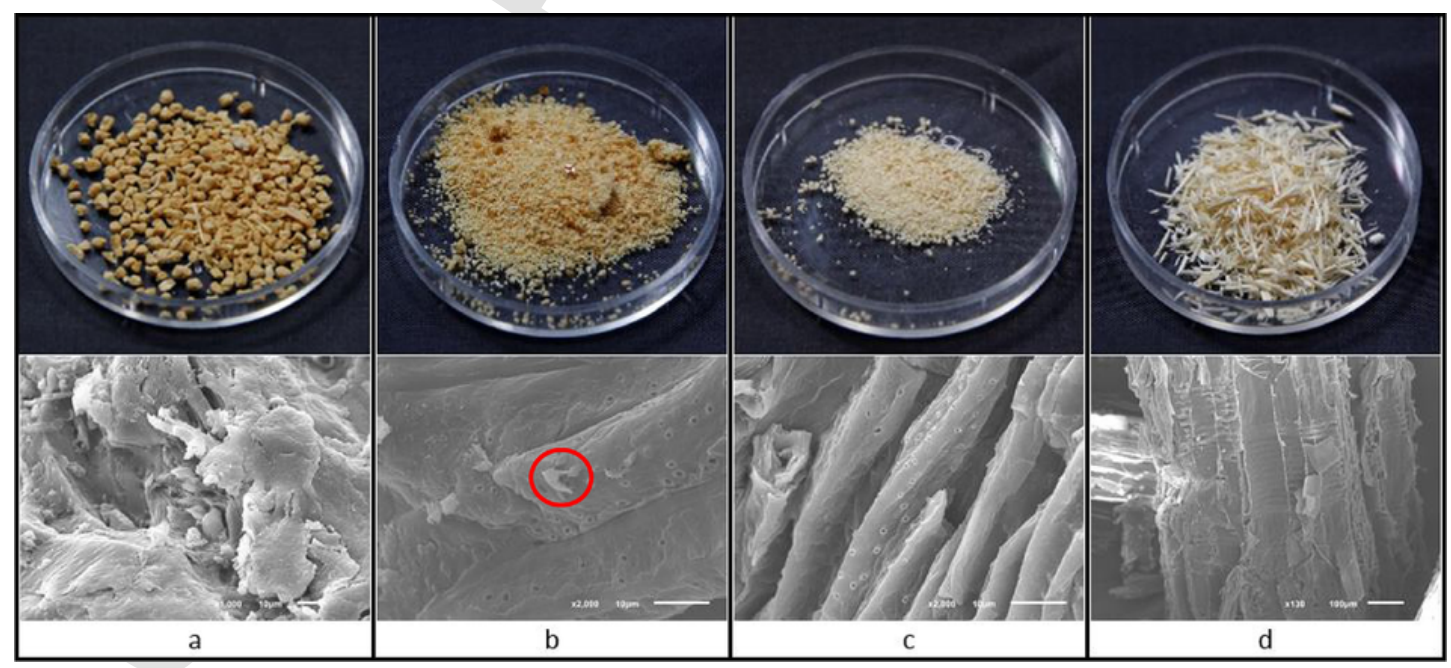

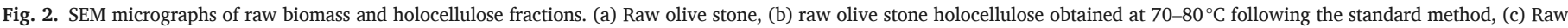
olive stone holocellulose isolated following the novel method, (d) cherry tree holocellulose obtained following the standard method. 
Table 2

Comparison between the ASTM D-1104 method and the novel method.

\begin{tabular}{lll}
\hline & ASTM D-1104 & $\begin{array}{l}\text { Novel method based on } \\
\text { ASTM D-1104 }\end{array}$ \\
\hline $\begin{array}{l}\text { Temperature } \\
\text { Reactants }\end{array}$ & $70-80^{\circ} \mathrm{C}$ & $96{ }^{\circ} \mathrm{C}$ \\
addition & $150 \mathrm{~mL} \mathrm{H}_{2} \mathrm{O}+1 \mathrm{~g}$ & $150 \mathrm{~mL} \mathrm{H}_{2} \mathrm{O}+5 \mathrm{~g}$ \\
$(2 \mathrm{~g}$ of & $\mathrm{NaClO}_{2}+0.2 \mathrm{~mL}$ & $\mathrm{NaClO}_{2}+1.08 \mathrm{~mL}$ \\
biomass $)$ & $\mathrm{CH}_{3} \mathrm{COOH}$ at the & $\mathrm{CH}_{3} \mathrm{COOH}$ at the \\
beginning & beginning \\
& $1 \mathrm{~g} \mathrm{NaClO}+0.22 \mathrm{~mL}$ & \\
Time & $\mathrm{CH} \mathrm{COOH}_{2}$ each hour (for & \\
Refrigeration & $5 \mathrm{~h})$ & $90 \mathrm{~min}$ \\
& $5 \mathrm{~h}$ & Yes \\
\hline
\end{tabular}

\subsection{Analysis of celluloses obtained from holocelluloses isolated following} the novel and standard methods

Since the novel method conditions are stronger than those corresponding to the standard one, a change of cellulose crystallinity could be taking place and hence, results obtained when using the novel method might be biased. In order to ascertain if major changes in cellulose crystallinity may occur, celluloses (Cel96 and Cel70) obtained from holocelluloses isolated following the novel (Holo96) and standard (Holo70) methods, were subjected to Differential Scanning Calorimetry (DSC). Microcrystalline cellulose (MCC) was used as a reference for determining the crystallinity degree of Cel96 and Cel70.

As can be seen in Fig. 3a, the thermogram of Cel96 shows two endothermic dips with minima at $141.6^{\circ} \mathrm{C}$ and $348.2^{\circ} \mathrm{C}$. The thermogram of the microcrystalline cellulose (MCC) used as reference also shows two endothermic dips with minima at $131.6^{\circ} \mathrm{C}$ and $342.6^{\circ} \mathrm{C}$. The first endothermic dip can be attributed to the presence of bound moisture in the cellulose samples that would evolve upon heating (Yang, Yan, Chen, Lee, \& Zheng, 2007). The second dip may be attributed to cellulose crystalline structure (Miranda, Bica, Nachtigall, Rehman, \& Rosa, 2013; Morán, Alvarez, Cyras, \& Vázquez, 2008; Rosa, Rehman, de Miranda, Nachtigall, \& Bica, 2012; Soares, Camino, \& Levchik, 1995; Yang et al., 2007). However, the endothermic dip corresponding to Cel96 is less pronounced than the one corresponding to MCC. In order to ascertain the reasons for this behavior, lignin content of Cel96 was determined and was found to be $2.3 \%$, by weight. According to litera- ture (Yang et al., 2007), it could be hypothesized that, at that high temperature, some lignin degradation to volatile compounds with the evolution of heat would be taking place, therefore giving to a less endothermic dip (Collard \& Blin, 2014; Domínguez-Robles et al., 2017; Naron, Collard, Tyhoda, \& Görgens, 2017; Yang et al., 2007). To check for the validity of this hypothesis, increasing amounts of commercial Kraft lignin were added to Cel96 to reach final lignin contents of 14 and $21 \%$, by weight, in the Cel96/Kraft lignin blends. As can be seen in Fig. 3a, as Kraft lignin content increases, the second thermogram dip becomes less endothermic. Furthermore, for Cel70 an exothermic peak with maxima at $350.2{ }^{\circ} \mathrm{C}$ was observed. This behavior is in good agreement with the higher lignin content of Cel70, which was found to be $26.6 \%$, by weight, thereby confirming the hypothesis previously posed regarding the exothermic degradation of lignin to volatile compounds.

While the overlapping of the exothermic peak corresponding to lignin degradation with the endothermic dip corresponding to cellulose crystalline structure decomposition precludes the determination of the degree of crystallinity by DSC, the observed behavior does not point to major crystallinity differences between Cel96 and Cel70.

\subsection{Crystallinity degree of holocelluloses isolated following the novel and standard methods}

The ultimate goal of holocellulose determination method is to provide a residue (the holocellulose) as pure as possible without any loss nor major change of holocellulosic components. However, under the stronger conditions of the novel method, there is a risk of loss in hemicellulose. To ascertain if a major change in the hemicellulose content of holocelluloses isolated following the standard (Holo70) and novel (Holo96) methods could have been taking place, samples of both kinds of holocelluloses were also subjected to Differential Scanning Calorimetry (DSC).

As can be seen in Fig. 3b, thermograms corresponding to both holocelluloses show a first endothermic dip and two exothermic peaks. The first dip (endothermic) seems to be due to the presence of bound moisture that would evolve upon heating. The second peak (exothermic) may be ascribed to hemicelluloses degradation upon heating (Yang et al., 2007). The third peak (exothermic) can be attributed to the aforementioned exothermic lignin degradation to volatile compounds, because lignin contents of Holo96 and Holo70 were determined to be 6 and $28 \%$, by weight, respectively. According to that stated in the Materials and Methods section, thermograms registered for Holo96 and Holo70 can be considered similar, and hence, any major change in the

Table 3

Compositional analysis of non-woody biomass samples when using the novel method.

\begin{tabular}{|c|c|c|c|c|c|c|c|c|}
\hline Biomass & $\begin{array}{l}\text { Extractives } \\
(\%)\end{array}$ & $\begin{array}{l}\text { Moisture } \\
(\%)\end{array}$ & $\begin{array}{l}\text { Holocellulose } \\
(\%)\end{array}$ & $\begin{array}{l}\text { Cellulose } \\
(\%)\end{array}$ & $\begin{array}{l}\text { Hemicellulose } \\
(\%)\end{array}$ & $\begin{array}{l}\text { Lignin } \\
(\%)\end{array}$ & Ash (\%) & $\begin{array}{l}\text { Total } \\
(\%)\end{array}$ \\
\hline Almond shell & 3.25 & $10.2 \pm 0.2$ & $58 \pm 2$ & $27 \pm 2$ & $30 \pm 2$ & $36 \pm 3$ & $0.5 \pm 0.1$ & $94 \pm 3$ \\
\hline $\begin{array}{l}\text { Dry olive oil } \\
\text { mill stone }\end{array}$ & 12.48 & $11.05 \pm 0.02$ & $68 \pm 4$ & $31 \pm 4$ & $37 \pm 4$ & $32.0 \pm 0.3$ & $0.43 \pm 0.01$ & $100 \pm 4$ \\
\hline $\begin{array}{l}\text { Extracted } \\
\text { olive pomace }\end{array}$ & 35.29 & $10 \pm 1$ & $40 \pm 3$ & $19 \pm 3$ & $22 \pm 3$ & $40.0 \pm 0.9$ & $3.45 \pm 0.07$ & $81 \pm 3$ \\
\hline $\begin{array}{l}\text { Extracted } \\
\text { olive pomace } \\
\text { pellets }\end{array}$ & 27.28 & $8 \pm 2$ & $44 \pm 3$ & $19 \pm 2$ & $24 \pm 2$ & $35.0 \pm 0.4$ & $3.90 \pm 0.02$ & $79 \pm 3$ \\
\hline Hazelnut shell & 3.74 & $9.7 \pm 0.2$ & $54 \pm 2$ & $30 \pm 2$ & $23 \pm 2$ & $38.0 \pm 0.5$ & $0.49 \pm 0.02$ & $92 \pm 2$ \\
\hline Nut shell & 3.73 & $9.8 \pm 0.1$ & $60 \pm 2$ & $37 \pm 3$ & $22 \pm 3$ & $36 \pm 3$ & $0.1500 \pm 5 \cdot 10^{-4}$ & $95 \pm 2$ \\
\hline $\begin{array}{l}\text { Olive pomace } \\
\text { oil-extractor }\end{array}$ & 12.59 & $10.04 \pm 0.03$ & $58 \pm 6$ & $29 \pm 5$ & $29 \pm 5$ & $34.0 \pm 0.4$ & $2.37 \pm 0.03$ & $92 \pm 6$ \\
\hline Pine nut shell & 3.89 & $10.0 \pm 0.2$ & $56 \pm 8$ & $31 \pm 5$ & $25 \pm 5$ & $38.0 \pm 0.8$ & $0.890 \pm 6 \cdot 10^{-3}$ & $94 \pm 8$ \\
\hline $\begin{array}{l}\text { Raw olive oil } \\
\text { mill stone }\end{array}$ & 4.98 & $8.99 \pm 0.07$ & $69 \pm 2$ & $30 \pm 2$ & $38 \pm 2$ & $34.0 \pm 0.3$ & $0.34 \pm 0.04$ & $102 \pm 2$ \\
\hline $\begin{array}{l}\text { Raw olive } \\
\text { stone }\end{array}$ & 2.26 & $9.29 \pm 0.04$ & $54 \pm 6$ & $27 \pm 4$ & $28 \pm 4$ & $37.0 \pm 0.3$ & $0.75 \pm 0.03$ & $91 \pm 6$ \\
\hline
\end{tabular}




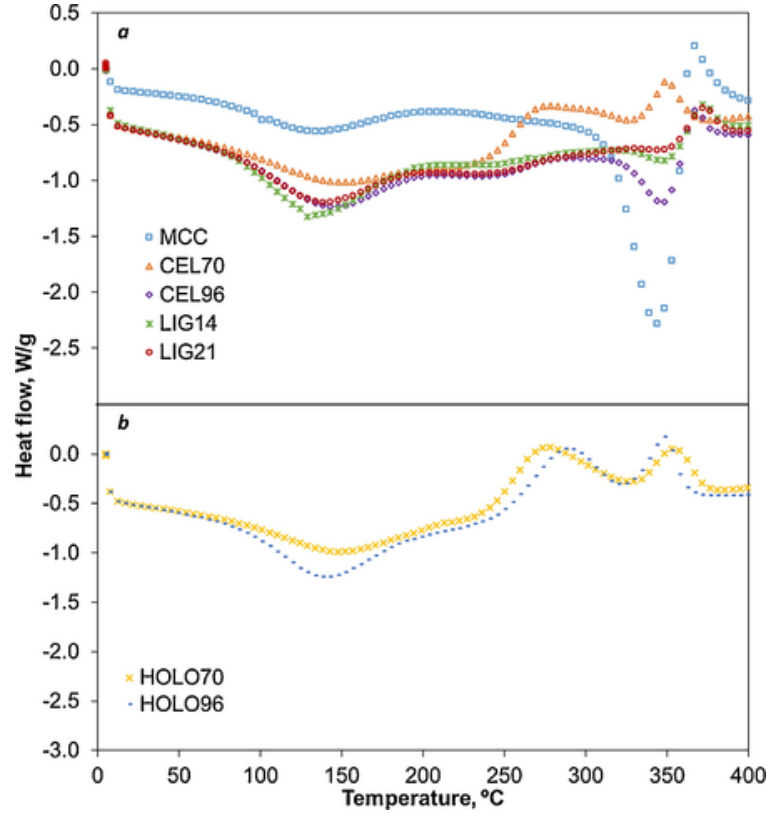

Fig. 3. DSC curves of (a) MCC, Cel70, Cel96, 14\% lignin-containing Cel96/Kraft lignin blend and 21\% lignin-containing Cel96/Kraft lignin blend and (b) Holo70 and Holo96.

hemicellulose content or crystallinity degree of holocelluloses isolated following the standard (Holo70) and novel (Holo96) methods can be discarded.

However, in order to compare the crystallinity degree of both holocelluloses, Holo70 and Holo96 samples were subjected to X-ray diffraction analysis (see Fig. 4b and c). MCC sample was used in order to validate the methodology (see Fig. 4a). Before calculating the values of the $I_{002}$ and $I_{a m}$ heights, the background intensity was subtracted for the experimental profiles of all the samples in order to calculate their crystallinity index (Park, Baker, Himmel, Parilla, \& Johnson, 2010; Terinte, Ibbett, \& Schuster, 2011).

The obtained crystallinity index value for the MCC sample was 91.9\%, similar to that published in the literature for microcrystalline cellulose samples (Ioelovich \& Veveris, 1987; Park et al., 2010). The diffraction pattern from Holo70 and Holo96 samples showed a similar minor crystallinity degree, and the values found $(60.0 \%$ and $68.0 \%$, respectively) were in good agreement with the X-ray powder diffraction profiles found by other authors (Poletto, Ornaghi, \& Zattera, 2014; Vieira \& Pasquini, 2014).

\subsection{Carbohydrate analysis of Holo70 and Holo96}

To ascertain whether the loss of carbohydrates is higher when applying the novel method than when using the standard one, the carbo-

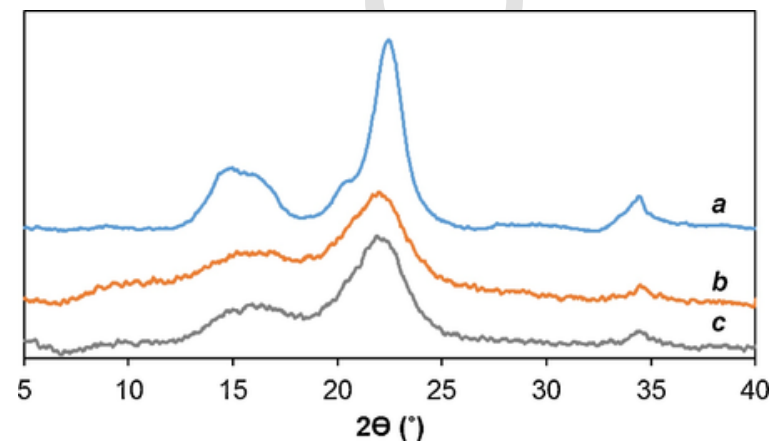

Fig. 4. X-ray powder diffraction profiles of (a) MCC, (b) Holo70 and (c) Holo96. hydrate content of both holocelluloses was determined by HPLC and compared. Only cellobiose, glucose and xylose were found and their amounts were found to be $2.01 \%, 36.65 \%$ and $31.12 \%$ for Holo70 and $1.82 \%, 42.80 \%$ and $30.90 \%$ for Holo96. Therefore, no significant differences between the monomeric composition of both holocelluloses were found. Consequently, the higher temperature of the novel method did not seem to affect the carbohydrate content although lignin degradation increased.

\subsection{Structural analysis of non-woody biomass according to the novel method}

Once the optimization of the novel method was carried out, a total amount of 10 non-woody biomass samples were analyzed using the novel method proposed in this paper. The structural composition is shown in Table 3. All holocellulose contents of samples ranged between 40 and $69 \%$. When the standard method was used, the holocellulose content determined for the raw olive stone sample was $95 \%$. However, when the novel method was used, the holocellulose content was found to be only $54 \%$. Raw olive oil mill and dry olive oil mill contained the highest quantities of holocellulose, while extracted olive pomace and extracted olive pomace pellets contained the lowest ones. All of the lignin contents were found to be in the $32-40 \%$ range.

Fig. 5 shows a ternary diagram to classify biomass based on structural composition (Vassilev et al., 2015). As can be seen in Fig. 5, non-woody biomass samples analyzed in this paper belong to the groups which have higher quantities of lignin such as LHC, LCH, HLC, and CLH. Previous results for woody biomass have been added in order to compare to non-woody biomass data (Álvarez et al., 2015). As can be seen, woody biomass belongs to completely different groups, such as those which have higher quantities of cellulose, that is CLH and CHL (Álvarez et al., 2015).

The standard methods work well for woody and herbaceous biomass (i.e., samples with higher contents of cellulose and hemicellulose than lignin, such as CLH, CHL, HCL and HLC groups). Most part of non-woody biomass samples studied in this paper belongs to groups in which lignin is the main component (i.e., LCH and LHC groups). There are also three samples which belong to groups with a higher amount of cellulose or hemicellulose than lignin (nut shell belongs to the CLH group, and dry olive oil mill stone and raw olive oil mill stone belong to the HLC group). However, these samples show a high amount of lignin and, therefore, they are very close to groups in which lignin is the main component (i.e., LCH and LHC groups). From our expertise in this field, we only found problems when isolating the holocellulose of samples belonging to the groups with a higher amount of lignin (LCH and LHC). Thus, the different group classifications enable to state if the holocellulose extraction process is going to be influenced by the location of a specific sample in the ternary diagram. The higher the sample lignin content, the higher the probability that our novel method be needed for isolating the holocellulose of biomass samples.

\section{Conclusions}

A novel method for holocellulose determination was developed. It mainly consists in a treatment with sodium chlorite and glacial acetic acid at boiling point. The novel method developed enables the determination of holocellulose in one-third of the time needed when using the standard method (i.e. from $5 \mathrm{~h}$ to just $90 \mathrm{~min}$ ).

The crystallinity index of holocellulose isolated by following the novel method remained unchanged compared to the holocellulose isolated by following the standard one. Moreover, during the holocellulose determination, the lignin degradation increased without losing of carbohydrates. 


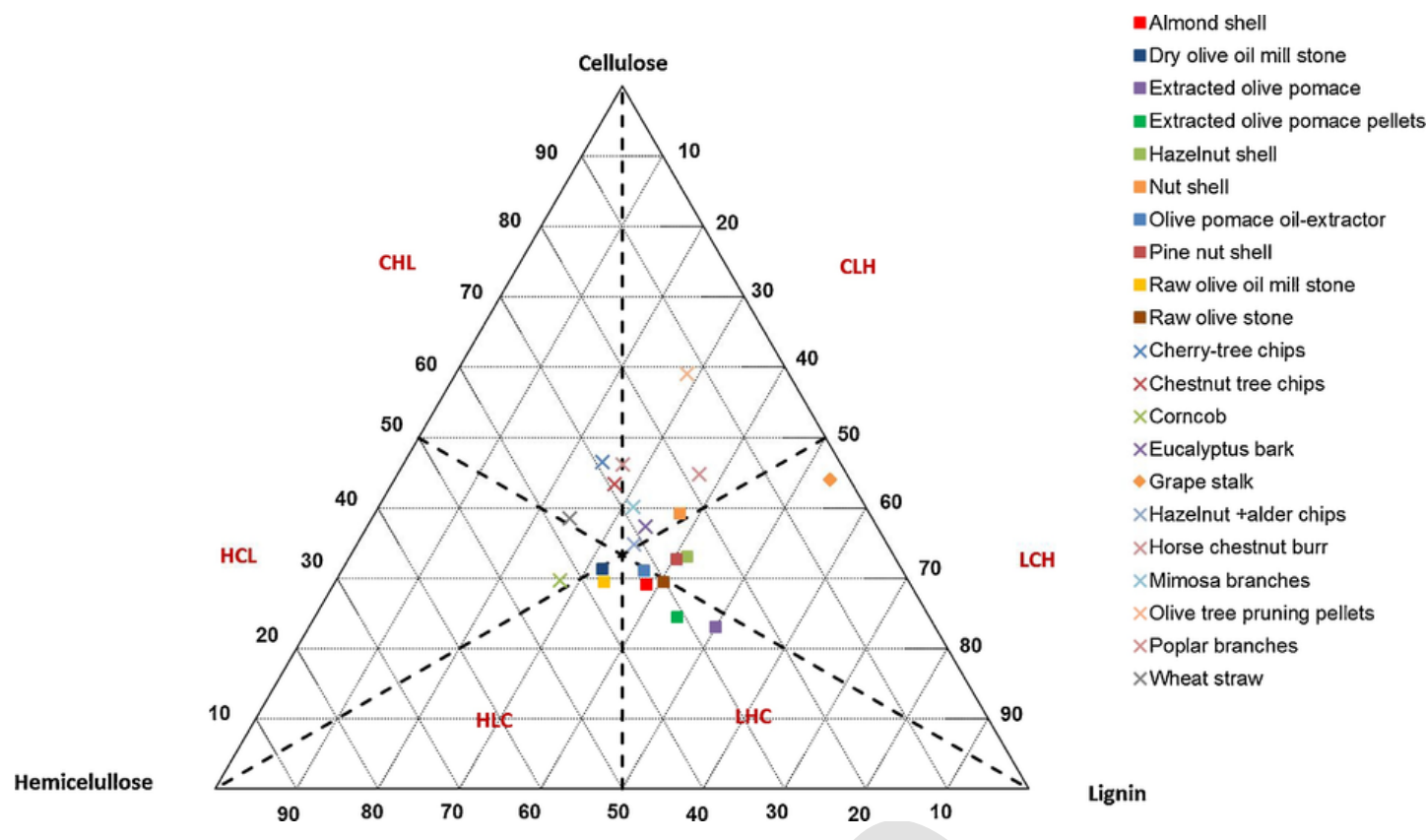

Fig. 5. Ternary diagram of structural composition of biomass.

Lignin was found to be the major component of non-woody biomass samples since most of them belong to LHC and LCH groups, which are completely different than the ones the woody biomass belongs to in the ternary diagram of the structural composition of biomass (i.e., CLH and CHL). This finding reveals that cellulose is not the main structural component in non-woody biomass samples since the amount of lignin is the largest in most of the samples. This is the main difference between woody and non-woody biomass samples.

\section{Acknowledgements}

This paper is greatly indebted to MINECO for the economic support given to the Normalized vegetable Biomass for Efficient Energetic Trigeneration project (MINECO-13-CTQ2013-45155-R) and Economic and Employment Office of the Principality of Asturias for the economic support given to the TRIBIONOR project (PCTI Asturias 2013-2017, Ref. FC-15-GRUPIN14-095).

Also, authors wish to gratefully acknowledge to the Government of the Principality of Asturias for supporting Ana Álvarez with a fellowship of its Severo Ochoa Program.

Finally, authors wish to deeply thank the companies Acciona, CarsanBio, Viñadecanes Vinos, Cooperativa Agrícola de Cangas del Narcea, Vino de la Tierra de Cangas and García Munté Energía for their assistance in supplying most of the samples necessary for studying the different kinds of biomass.

\section{References}

Álvarez, A., Pizarro, C., García, R., Bueno, J.L., 2015. Spanish biofuels heating value estimation based on structural analysis. Industrial Crops and Products 77, 983-991. https: //doi.org/10.1016/j.indcrop.2015.09.078.

ASTM International, 1978. ASTM D1104-56 (1978) method of test for holocellulose in wood (withdrawn 1985).

Agencia Andaluza de la Energía, 2016. La biomasa en Andalucía. Agencia Andaluza de la Energía, Retrieved from https://www.agenciaandaluzadelaenergia.es/sites/default/ files/documentos/la_biomasa_en_andalucia_noviembre_2016.pdf.

Angelini, S., Cerruti, P., Immirzi, B., Scarinzi, G., Malinconico, M., 2016. Acid-insoluble lignin and holocellulose from a lignocellulosic biowaste: Bio-fillers in poly(3-hydroxybutyrate). European Polymer Journal 76, 63-76. https://doi.org/10.1016/j. eurpolymj.2016.01.024.
Collard, F.-X., Blin, J., 2014. A review on pyrolysis of biomass constituents: Mechanisms and composition of the products obtained from the conversion of cellulose, hemicelluloses and lignin. Renewable and Sustainable Energy Reviews 38, 594-608. https:// doi.org/10.1016/j.rser.2014.06.013.

Demirbaş, A., 2001. Relationships between lignin contents and heating values of biomass. Energy Conversion and Management 42 (2), 183-188. https://doi.org/10.1016/ S0196-8904(00)00050-9.

Domínguez-Robles, J., Sánchez, R., Díaz-Carrasco, P., Espinosa, E., García-Domínguez, M.T., Rodríguez, A., 2017. Isolation and characterization of lignins from wheat straw: Application as binder in lithium batteries. International Journal of Biological Macromolecules 104, 909-918. https://doi.org/10.1016/j.ijbiomac.2017.07.015.

elEconomista.es (2017, April 18). La biomasa de origen agrícola pide paso. Retrieved October 17, 2017, from http://www.eleconomista.es/aragon/noticias/8299790/04/17/ La-biomasa-de-origen-agricola-pide-paso.html.

Eurostat, 2015. Crop statistics (from 2000 onwards), Retrieved October 132017 from http: //appsso.eurostat.ec.europa.eu/nui/submitViewTableAction.do.

Ioelovich, M., Veveris, G.P., 1987. Determination of cellulose crystallinity by X-ray diffraction method. J. Wood Chemistry 5, 72-80.

Müller-Hagedorn, M., Bockhorn, H., Krebs, L., Müller, U., 2002. Investigation of thermal degradation of three wood species as initial step in combustion of biomass. Proceedings of the Combustion Institute 29 (1), 399-406. https://doi.org/10.1016/ S1540-7489(02)80053-0.

Miranda, M.I.G., Bica, C.I.D., Nachtigall, S.M.B., Rehman, N., Rosa, S.M.L., 2013. Kinetical thermal degradation study of maize straw and soybean hull celluloses by simultaneous DSC-TGA and MDSC techniques. Thermochimica Acta 565, 65-71. https://doi. org/10.1016/j.tca.2013.04.012.

Morán, J.I., Alvarez, V.A., Cyras, V.P., Vázquez, A., 2008. Extraction of cellulose and preparation of nanocellulose from sisal fibers. Cellulose 15 (1), 149-159. https://doi. org/10.1007/s10570-007-9145-9.

Moudache, M., Colon, M., Nerín, C., Zaidi, F., 2016. Phenolic content and antioxidant activity of olive by-products and antioxidant film containing olive leaf extract. Food Chemistry 212, 521-527. https://doi.org/10.1016/j.foodchem.2016.06.001.

Naron, D.R., Collard, F.-X., Tyhoda, L., Görgens, J.F., 2017. Characterisation of lignins from different sources by appropriate analytical methods: Introducing thermogravimetric analysis-thermal desorption-gas chromatography-mass spectroscopy. Industrial Crops and Products 101, 61-74. https://doi.org/10.1016/j.indcrop.2017.02.041.

Park, S., Baker, J.O., Himmel, M.E., Parilla, P.A., Johnson, D.K., 2010. Cellulose crystallinity index: measurement techniques and their impact on interpreting cellulase performance. Biotechnology for Biofuels 3, 10. https://doi.org/10.1186/ 1754-6834-3-10.

Poletto, M., Ornaghi, H.L., Zattera, A.J., 2014. Native cellulose: Structure, characterization and thermal properties. Materials 7 (9), 6105-6119. https://doi.org/10.3390/ ma7096105.

Rabemanolontsoa, H., Saka, S., 2012. Holocellulose determination in biomass. Zero-carbon energy Kyoto 2011. Springer, Tokyo, 135-140. https://doi.org/10.1007/ 978-4-431-54067-0_14.

Rabemanolontsoa, H., Ayada, S., Saka, S., 2011. Quantitative method applicable for various biomass species to determine their chemical composition. Biomass and Bioenergy 35 (11), 4630-4635. https://doi.org/10.1016/j.biombioe.2011.09.014. 
Rodríguez, G., Lama, A., Rodríguez, R., Jiménez, A., Guillén, R., Fernández-Bolaños, J., 2008. Olive stone an attractive source of bioactive and valuable compounds. Bioresource Technology 99 (13), 5261-5269. https://doi.org/10.1016/j.biortech.2007.11. 027.

Rosúa, J.M., Pasadas, M., 2012. Biomass potential in Andalusia, from grapevines, olives, fruit trees and poplar, for providing heating in homes. Renewable and Sustainable Energy Reviews 16 (6), 4190-4195. https://doi.org/10.1016/j.rser.2012.02.035.

Rosa, S.M.L., Rehman, N., de Miranda, M.I.G., Nachtigall, S.M.B., Bica, C.I.D., 2012. Chlorine-free extraction of cellulose from rice husk and whisker isolation. Carbohydrate Polymers 87 (2), 1131-1138. https://doi.org/10.1016/j.carbpol.2011.08.084.

Secretaría General Técnica, Subdirección General de Estadística, 2016. Encuesta sobre superficies y rendimientos de cultivos. Resultados 2016 (No. 013-17-120-0). Ministerio de Agricultura y Pesca, Alimentación y Medio Ambiente.

Segal, L., Creely, J.J., Martin, A.E., Conrad, C.M., 1959. An empirical method for estimating the degree of crystallinity of native cellulose using the X-ray diffractometer. Textile Research Journal 29 (10), 786-794. https://doi.org/10.1177/ 004051755902901003.

Šimkovic, I., Kelnar, I., Mendichi, R., Bertok, T., Filip, J., 2017. Composite films prepared from agricultural by-products. Carbohydrate Polymers 156, 77-85. https://doi.org/ 10.1016/j.carbpol.2016.09.014.

Sluiter, A., Hames, B., Ruiz, R., Scarlata, C., Sluiter, J., Templeton, D., 2005. Determination of ash in biomass: Laboratory analytical procedure (LAP). National Renewable Energy Laboratory.

Sluiter, A., Hames, B., Ruiz, R., Scarlata, C., Sluiter, J., Templeton, D., et al., 2008. Determination of structural carbohydrates and lignin in biomass: Laboratory analytical procedure (LAP) (Revised august 2012). National Renewable Energy Laboratory.

Sluiter, J.B., Ruiz, R.O., Scarlata, C.J., Sluiter, A.D., Templeton, D.W., 2010. Compositional analysis of lignocellulosic feedstocks. 1. Review and description of methods.
Journal of Agricultural and Food Chemistry 58 (16), 9043-9053. https://doi.org/10. 1021/jf1008023.

Soares, S., Camino, G., Levchik, S., 1995. Comparative study of the thermal decomposition of pure cellulose and pulp paper. Polymer Degradation and Stability 49 (2), 275-283. https://doi.org/10.1016/0141-3910(95)87009-1.

TAPPI, 2002. TAPPI-T-212-om-12. One percent sodium hydroxide solubility of wood and pulp.

TAPPI, 2007. TAPPI T-264 cm-07. Preparation of wood for chemical analysis.

Terinte, N., Ibbett, R., Schuster, K.C., 2011. Overview on native cellulose and microcrystalline cellulose I structure studied by X-ray diffraction (waxd): Comparison between measurement techniques. Lezinger-Berichte 89, 118-131.

Vassilev, S.V., Vassileva, C.G., Vassilev, V.S., 2015. Advantages and disadvantages of composition and properties of biomass in comparison with coal: An overview. Fuel 158, 330-350. https://doi.org/10.1016/j.fuel.2015.05.050.

Vecino, X., Devesa-Rey, R., Cruz, J.M., Moldes, A.B., 2015. Study of the physical properties of calcium alginate hydrogel beads containing vineyard pruning waste for dye removal. Carbohydrate Polymers 115, 129-138. https://doi.org/10.1016/j.carbpol. 2014.08.088.

Vieira, F.S., Pasquini, C., 2014. Determination of cellulose crystallinity by terahertz-time domain spectroscopy. Analytical Chemistry 86 (8), 3780-3786. https://doi.org/10. 1021/ac4035746.

Wise, L.E., 1946. Chlorite holocellulose, its fractionation and bearing on summative wood analysis and studies on the hemicelluloses. Paper Trade Journal 122 (2), 35-43.

Yang, H., Yan, R., Chen, H., Lee, D.H., Zheng, C., 2007. Characteristics of hemicellulose, cellulose and lignin pyrolysis. Fuel 86 (12-13), 1781-1788. https://doi.org/10.1016/ j.fuel.2006.12.013.

Yeh, T.-F., Chang, H., Kadla, J.F., 2004. Rapid prediction of solid wood lignin content using transmittance near-infrared spectroscopy. Journal of Agricultural and Food Chemistry 52 (6), 1435-1439. https://doi.org/10.1021/jf034874r. 